\title{
How Low Income People Perceived Poverty? A Preliminary Findings on Poverty Attribution of B40 Group in Malaysia
}

\author{
Norizan Hassan, Rozmi Ismail, Nurul-Azza Abdullah
}

\begin{abstract}
Studies on understanding psychological aspects of poverty in specific population like Malaysia are very rare. Thus the causes of poverty especially among $B 40$ groups whether is related to individual (internal) or external factors is questionable. Previous literatures indicated that there are three (3) causal attribution of poverty, that is structuralistic, individualistic, and fatalistic. This study examines the perception of B40 youth in Malaysia with regard to the causes of poverty. A total of $112 \mathrm{~B} 40$ youth aged 15 to 25 years old (male $=40$, female $=72$ ) in Selangor Malaysia involved in this study. Purposive sampling method was used for selecting of respondent based on the criteria on $B 40$ youth. For the purpose of validating the instrument, a factor analysis was used. The results of this study showed that B40 youth in our sample used three (3) causal attributions of poverty; that is individualistic, followed by structuralistic and fatalistic which supporting the results of previous studies. The implication of the study will contribute to the understanding of the mind of B40 groups in Malaysia.
\end{abstract}

Keywords : B40 group, attribution, poverty, youth.

\section{INTRODUCTION}

$\mathrm{I}_{\mathrm{n}}$ Malaysia, poverty issues are often associated with the low-income group or known as B40 (Bottom 40 percent of the population). According to Malaysia Department of Statistics (2016) individual or family who received monthly income less than RM 4,360 per-month is categorized as B40 group. The high number of B40 in the city may have represented a large number of households residing in the city due to migration from rural to city. One of the factors of poverty prevailing among the people in the city is the high cost of living with the static revenue. Malaysia has now rapidly affected by the increased cost of living in the city that is not in line with earnings.

\section{LITERATURE REVIEW}

Most studies on poverty were related the phenomena with psychological factors including human perception, attitude, and attribution (Furham 2003). To understand the causes of

Revised Manuscript Received on September 25, 2019

Norizan Hassan, Psychology \& Human Well-Being Research Centre, Faculty of Science Social and Humanities, Universiti Kebangsaan Malaysia, Bangi, Malaysia. Email: izhaz_30@yahoo.com

Rozmi Ismail, Psychology \& Human Well-Being Research Centre, Faculty of Science Social and Humanities, Universiti Kebangsaan Malaysia, Bangi, Malaysia. Email: rozmi@ukm.edu.my

Nurul-Azza Abdullah, Psychology \& Human Well-Being Research Centre, Faculty of Science Social and Humanities, Universiti Kebangsaan Malaysia, Bangi, Malaysia. Email: nurulazza@ukm.edu.my poverty, studies generally bumped into the attribution theories that emphasize internal and external factors (Heider 1958). Feagin (1972) mapped out internal and external factors into three (3) dimensions; individualistic, structuralistic, and fatalistic. However, several studies report that structural and individualistic factors have several subcategories to adapt with sample's background. Thus, this study have considered background and cultural aspect of B40 youth to develop the instrument.

Attribution can be defined as the process of making a conclusion on the cause of an event using certain information (Ismail 2011). Internal factor refer to attributing poverty due to oneself while external factor refers to the tendency of attributing poverty due to situations that an individual faced (Ismail 2011; Heider 1958). Internal factor that cause poverty are related to individual internal sources such as personality, attitude and effort while external factor are related to influences by the others, lack of help, fate and the provision of God. However, some studies found that the dimensions of causal attribution of poverty are also influenced by different background and cultures. Most studies on the causal attribution of poverty found three (3) key factors, namely individualistic, structural and fatalistic (Feagin (1972; Wilson 1987). Individualistic emphasizes on the individual aspects as the cause of poverty while structuralistic emphasizes on external factors such as unemployment and the source of income. Fatalism, on the other hand, emphasizes aspect of destiny beyond human control such as misfortune and accident (Feagin 1972; Morcol 1997).

Feagin's (1972) study using American sample became the basis for subsequent studies in the study of poverty attribution. However, according to the literature, there have been studies that categorize individualistic and structural factors into several subcategories depending on the suitability of respondents who were heavily influenced by economic, political, social and cultural aspects. For example, studies in Lebenon have incorporated elements of 'status quo' (referring to current situations such as number of children, illnesses) and societies (referring to migration, morals and skills) to suit the respondents of the study (Naseer \& Abouchedid 2001). Similarly to student respondents in Crotia, researchers place micro-environmental factors aside from structural factors that are more socially desirable (Ljubotina \& Ljubotina 2007).

The factor analysis results from previous studies reported that there were between three (3) to six (6) factors that maintains individualistic and 


\section{How Low Income People Perceived Poverty?}

\section{A Preliminary Findings on Poverty Attribution of B40 Group in Malaysia}

fatalistic factors. Most structuralistic factor were divided into several factors to suit different study backgrounds. For example, Naseer \& Abouchedid (2001) found four (4) factors with individualistic factors divided into two (2) namely the status quo and blaming poverty / society, and structuralistic and fatalistic factors. Nasser, Singhal \& Abouchedid (2005) also found that there are six (6) poverty factors which are individualistic (external), individualistic (internal), structuralistic (execution), social, wrong policy and fatalistic. In addition, Ljubotina and Ljubotina (2007) found that there were four (4) factors namely individual, structural / social, micro-environment, and fatalistic. The results of Wollie's (2009) study showed that there were only three (3) factors that are individualistic, structuralistic, and fatalistic.

There are not many studies in Malaysia that focus on poverty attribution. However, there are studies that used students as their sample. Among them are the study of Azlina and Ma'rof (2013) which studied students of Orang Asli (Indigenous people) in Pahang and Perak, aged ranges from 14 to 16 years. This study found that students of an Indigenous people were more likely to use economic attribution to explain their condition (which refers to one of the structural attributions). The study of Murnizam et. al (2012) who studied Malaysian students in the United Kingdom also found that youths were more likely to use structural attribution in perceiving their poverty condition.

Most studies on poverty attribution among youth involved students or college students as sample and their findings generally found that adolescent were more likely to use structural attribution than others when explain their poverty condition. Studies in abroad such as in Labenon (Naseer \& Abouchedid 2001), India (Nasser, Singhal and Abouchedid 2005) and Crotia (Ljubotina \& Ljubotina 2007) also found that youths were more likely to have structural attribution. However, there are couple of studies that showed different results. For example, Samuel and Ernest (2012) study found that fatalistic students in Ghana were more likely to use individualistic attribution.

Although most studies abroad on youth have found that youth were more likely to use structural attribution, other aspects need to be taken into account such as demographic, cultural and socioeconomic factors. It is hypothesized that these factors appeared to have influenced the pattern of poverty attribution among youth.

With regard to the above, this study aims to examine the patterns of poverty attribution among Malaysia's B40 youth. This research is very significant and in-line with the government policy to eradicate poverty issues among B40 groups. Moreover, it is important to understand B40 youth; and their perception towards poverty may be different as compared to adults. The findings of this kind of study will be useful to any related agencies to understand attribution pattern of young generation of B40 groups, it will also help them to formulate more effective intervention on addressing the issues pertaining to poverty cycle. With regard to the above, the study aimed to (1) develop the items of instrument that measure causal attribution of poverty, (2) test the reliability and validity of instrument, and (3) identify the most important causes of poverty among B40 youth.

\section{METHOD}

\section{A. Study and Method Design}

This study employed a survey method using validated instruments. Informed consent was given and signed by the respondents to maintain their confidentiality. The researcher provided a brief description of the questionnaire and helped clarify to the respondent if any item was unclear. The study is part of the bigger scale research project funded by The Universiti Kebangsaan Malaysia. The survey was conducted between Jun 2018- May 2019.

\section{B. Sample}

Gursuch (1983) and Kline (1979) recommended that the sample size in factor analysis should be at least 100. A total of 112 respondents have participated in this study. Hence, this study has fulfilled the criteria of sampling in factor analysis.

The respondents were youths aged 15 to 25 made up of 40 men (35.7 per cent) and 72 (64.3 per cent) women in Selangor. All respondents were Malay Muslim Youths with households incomes below RM4,360, who were also categorized as B40 were selected to study samples using the targeted sampling method.

Number of respondents and their socio-demographic characteristics is shown in Table 1 . Table 1 indicates that respondents were comprised of several categories of income. Most respondents had an income range of between RM 1000 and RM 3000. 34.6 per cent of respondents had RM1001 to RM 2000 and 26.8 per cent of respondents were RM 2001 to RM 3000.

Table 1: Socio- demographic characteristics of respondents

\begin{tabular}{|l|c|c|}
\hline \multicolumn{1}{|c|}{ Demographic } & Total & Percentage (\%) \\
Age & & \\
15-18 years & 38.4 & 38.4 \\
19-25 years & 61.6 & 61.6 \\
\hline Gender & & \\
Male & 40 & 35.7 \\
Female & 72 & 64.3 \\
\hline Monthly Income & & \\
Below RM 1000 & 23 & 20.5 \\
RM 1001 - RM 2000 & 39 & 34.8 \\
RM 2001 - RM 3000 & 30 & 26.8 \\
RM 3000 above & 20 & 17.9 \\
\hline
\end{tabular}

\section{Instrument}

The questionnaire was divided into two (2) sections. The first section contains respondents' background information such as age, gender and income. The second section contains instruments that measure respondents' poverty attribution patterns that require respondents to respond to statements of cause on poverty using a rating scale of 1 (strongly disagree) to 2 (strongly agree). The instrument contains 17 items modified from previous studies based on Feagin (1972) research. This instrument were then translated using back to back translation by professional researchers. Factor analysis was performed for validation of the test instrument. 


\section{RESULTS AND DISCUSSION}

\section{A. Item development}

There were 17 items based on previous studies namely Naseer \& Abouchedid (2001), Nasser, Singhal and Abouchedid (2005), Ljubotina \& Ljubotina (2007), Wollie (2009), Murnizam et al (2012), Azlina and Ma 'rof (2013), Ige and Nekhwevha (2014) and Nishimwe-Niyimbanira (2014).
Table 2 shows the source of the last study for each item. Most of these studies took a sample of students and low-income groups. The items selected were considered to be relevant to the respondents' survey and culture in Malaysia. The meeting was conducted with a team of researchers from the National University of Malaysia from psychology and economic backgrounds to refine the items to fit the study sample.

Table 2: Items development based on past literature

\begin{tabular}{|l|c|c|}
\hline \multicolumn{1}{|c|}{ Statement } & Factor & Literature sources \\
\hline The government is lack in providing of public facilities & Structuralistic & 5,6 \\
\hline The education system is less emphasize on skills. & Structuralistic & $1,2,5,6,7$ \\
\hline The government is lack in providing of housing assistance. & Structuralistic & 1 \\
\hline The government is lack in providing of health service & Structuralistic & $1,2,5,6$ \\
\hline There is less on supporting agriculture. & Structuralistic & $1,5,6$ \\
\hline Poor family situation. & Structuralistic & 4,8 \\
\hline Lack of job opportunities. & Structuralistic & $1,5,6$ \\
\hline Low salary. & Structuralistic & $2,6,7$ \\
\hline Lack of effort to improve living conditions. & Individualistic & $5,6,7$ \\
\hline Lack of skills in getting a job. & Individualistic & $1,2,6,7$ \\
\hline Don't know how to manage money well. & Individualistic & 6 \\
\hline Don't know how to spend time with beneficial activities. & Individualistic & 6 \\
\hline Lack of motivation to improve themselves. & Individualistic & $5,6,7$ \\
\hline The power of God is inevitable. & Fatalistic & $2,3,4,6,7$ \\
\hline Bad luck. & Fatalistic & $1,2,3,4,5,6,7,8$ \\
\hline Accident or natural disaster. & Fatalistic & 4,6 \\
\hline Fate. & Fatalistic & $1,2,3,4,7,8$ \\
\hline
\end{tabular}

Notes:

1 = Nasser dan Abouchedid (2001), 2 = Nasser, Singhal dan Abouchedid (2005), 3 = Ljubotina dan Ljubotina (2007), $4=$

Wollie (2009), 5 = Murnizam et al (2012), 6 = Azlina dan Ma'rof (2013), 7 = Ige dan Nekhwevha (2014),

$8=$ Nishimwe-Niyimbanira (2014)

\section{B. Testing the Reliability and Validity Instrument}

The reliability of each factor was tested using Cronbach Alpha coefficient values which showed good reliability with structuralistic attribution factors (Cronbach Alpha $=0.773$ ), individualistic attribution (Cronbach Alpha = 0.752) and fatalistic attribution (Cronbach Alpha $=0.662$ ). The validity of the content of the test instrument was done using exploratory factor analysis (EFA). Principal component analysis with varimax rotation has been used with several criteria. Among the criteria is that each factor must have an Eigen value greater than one and the item will be retained when the load is equal to or greater than 0.30 (Geggie et al. 2000; Hair et al. 1998; Lewis-Beck, 1994).

In the early stages of factor analysis, the results showed that there were six (6) factors with greater than one Eigen value, contributing to 66.68 percent variance. Based on the 'scree plot' distribution, the researcher has identified three (3) factors to be retained for further factor analysis. Zwick and Velicer (1982) state that the 'scree plot' is likely to be a more accurate determinant of the number of factors that need to be maintained in factor analysis.

Table 3 shows the solution of three (3) factors after factor rotation. All three factors accounted for 47.51 percent of the variance for B40 youth. The structuralistic attribution factor accounted for 23.83 percent of the variance with a factor loading of 0.374 to 0.781 . Structuralistic attribution shows that B40 youth attributed poverty to poor infrastructure (such as public facilities, housing and health services), education, income and employment. Individualistic factors accounted for 12.19 percent of the variance with a factor loading of 0.551 to 0.760. Individualistic attributional factors indicated that respondents were tend to view aspects of themselves as causes of poverty such as lack of effort and competition, lack of motivation and lack of knowledge of the time and money available. Fatalistic attribution factors also indicated that respondents were more likely to blame fate, events and gods as the cause of poverty. This attribution accounts for 11.49 percent of the variance with a factor loading of 0.559 to 0.838 .

Overall, the results show that the test equipment has good reliability and validity. The factor analysis results also supported the findings of most previous studies that divide into three (3) key dimensions of attribution of youth B40 poverty. Although there were previous studies such as Nasser, Singhal \& Abouchedid (2005) in India and Ljubotina and Ljubotina (2007) in Crotia, which divide structuralistic attributions into several dimensions, B40 youths do not tend to ascribe the causes of poverty to more specific structuralistic dimension. This is because differences in attribution are influenced by cultural differences and local values

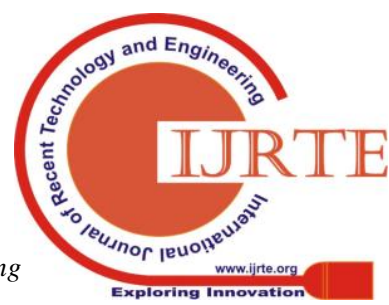


How Low Income People Perceived Poverty?

A Preliminary Findings on Poverty Attribution of B40 Group in Malaysia

Table 3: Factor Analysis on causes of poverty

\begin{tabular}{|c|c|c|c|}
\hline Item & $\begin{array}{c}\text { Factor } \\
1 \\
\end{array}$ & $\begin{array}{c}\text { Factor } \\
2 \\
\end{array}$ & $\begin{array}{c}\text { Factor } \\
\mathbf{3} \\
\end{array}$ \\
\hline $\begin{array}{l}\text { Factor 1: Structuralistic Attribution ( } \alpha=0.773) \\
\text { The government is lack in providing of public facilities } \\
\text { The education system is less emphasize on skills. } \\
\text { The government is lack in providing of housing assistance. } \\
\text { The government is lack in providing of health service } \\
\text { There is less on supporting agriculture. } \\
\text { Poor family situation. } \\
\text { Lack of job opportunities. } \\
\text { Low salary. }\end{array}$ & $\begin{array}{l}.781 \\
.722 \\
.672 \\
.635 \\
.564 \\
.554 \\
.479 \\
.374\end{array}$ & & \\
\hline $\begin{array}{l}\text { Factor 2: Individualistic Attribution }(\alpha=0.752) \\
\text { Lack of effort to improve living conditions. } \\
\text { Lack of skills in getting a job. } \\
\text { Don't know how to manage money well. } \\
\text { Don't know how to spend time with beneficial activities. } \\
\text { Lack of motivation to improve themselves. }\end{array}$ & & $\begin{array}{l}.760 \\
.707 \\
.707 \\
.660 \\
.551\end{array}$ & \\
\hline $\begin{array}{l}\text { Factor 3: Fatalistic Attribution }(\alpha=0.662) \\
\text { The power of God is inevitable. } \\
\text { Bad luck. } \\
\text { Accident or natural disaster. } \\
\text { Fate. }\end{array}$ & & & $\begin{array}{l}.838 \\
.698 \\
.667 \\
.559\end{array}$ \\
\hline $\begin{array}{l}\text { Eigenvalue } \\
\text { Percent of variance explained } \\
\text { Cumulative percent of variance explained }\end{array}$ & $\begin{array}{c}4.050 \\
23.825 \\
23.825\end{array}$ & $\begin{array}{c}2.073 \\
12.194 \\
36.019\end{array}$ & $\begin{array}{c}1.953 \\
11.490 \\
47.509\end{array}$ \\
\hline KMO Measure of Sampling Adequency & & & 0.690 \\
\hline $\begin{array}{l}\text { Barlet's Test of Sphericity } \\
\text { Approx. Chi-Square } \\
\text { df } \\
\text { Sig. }\end{array}$ & & & $\begin{array}{c}539.332 \\
136 \\
.000\end{array}$ \\
\hline
\end{tabular}

Extraction Method: Principal Component Analysis; Rotation Method: Varimax

\section{Identification of the Main Factor for Poverty Attribution}

Based on the factor analysis, the causal attribution of poverty among B40 youth are categorized into three (3) factors, namely structural, individual and fatalistic attribution. Table 4 below shows the average value of overall poverty attribution among youth B40. The highest average values were individualistic attribution (3.38), followed by structuralistic attribution (3.25) and lowest fatalistic attribution (3.11).

Table 4: Dimension of Causal Attribution of Poverty

\begin{tabular}{|c|c|c|c|c|}
\hline Dimension & Mean & S.D & Minimum & Maksimum \\
\hline Structuralistic & 3.25 & 0.67 & 1.38 & 4.63 \\
\hline Individualistic & 3.38 & 0.81 & 1.00 & 4.80 \\
\hline Fatalistic & 3.11 & 0.83 & 1.00 & 5.00 \\
\hline
\end{tabular}

Notes: S.D = Standard Deviation

The results of this study showed that attribution of causes of youth poverty B40 is more likely to attribute poverty to individualistic factors than structuralistic and fatalistic. This proved that most B40 youth see the inner aspect of the individual as more important than the external aspects such as basic amenities, job opportunities and low income. Although most previous studies have shown that youth factors are more likely to contribute to the cause of poverty in terms of external factors, they are different from the findings. Similarly, the study of Murnizam et. al (2012) who studied Malaysian students in the United Kingdom found that youths were more likely to use structural attribution. Thus, it can be seen that the factors of value and culture can influence the pattern of attribution. For example, the religious values in Islam held by the respondents influence the respondents not to blame their fate only in the face of difficulties.

\section{CONCLUSION}

This study aimed to develop and test the reliability and validity of test tools that measure the attribution of causes of poverty 
using a B40 youth sample. The Cronbach Alpha values for each factor showed good reliability. The factor analysis of the EFA supports the previous finding which overall outlines the attribution of the causes of poverty as multidimensional. The results of this study found that there are three (3) main factors as dimensions of causal attribution of poverty namely structuralistic attribution, individualistic attribution and fatalistic attribution. The results of this study also found that the most common cause of poverty among B40 youth was individualistic, followed by structuralistic and fatalistic. Therefore, it is recommended that the authorities focus more on programs that educate the youth of B40 to help them address the issue of poverty

\section{ACKNOWLEDGMENT}

This study is funded by the UKM Grand Challenge Grant Schme (DCP-2017-014/2). Acknowledgments of gratitude also to the research team who contributed so much during data collection.The researcher also thanked the respondents for their cooperation in this study.

\section{REFERENCES}

1. Azlina Mohd Khir \& Ma'rof Redzuan. 2013. Atribusi Kemiskinan dalam Kalangan Pelajar Orang Asli di Malaysia. Paper presented at International Conference on Social Science Research (ICSSR) 2013 4-5 Jun 2013, Penang Malaysia organized by WorldConference.net.

2. Feagin, J.R. 1972. Poverty: We Still believe that God helps those who themselves. Psychology Today 6: 101-129.

3. Furnham, A. 2003. Poverty and wealth. In. Carr, S.C \& Sloan, T. S (Eds.) Poverty and psychology: From global perspective to local practice, page 163-183. New York: Kluwer Academic/Plenum Publishers.

4. Geggie, J., DeFarin, J., Hitchcock, S., \& Simone, S. 2000. Family strengths research project. The Family Action Centre, University of Newcastle, Australia.

5. Gursuch, R.L., 1983. Factor Analysis ( $2^{\text {nd }}$ Ed.). Hillsdale, N.J. Erlbaum.

6. Hair, J. F., Anderson, R. E., Tantham, R. L., \& Black W. C. 1998. Multivariate data analysis (5th ed.). New Jersey: Prentice Hall.

7. Heider, F. 1958. The psychology of interpersonal relations. New York: Wiley.

8. Ige, K.D. 2014. The Layering of Poverty Attribution among Disadvantaged Groups In The Developing World. Mediterranean Journal of Social Sciences 5 (20).

9. Kline, P., 1994. An Easy Guilde To Factor Analysis. New York: Routhledge.

10. Lewis-Beck, M. S. 1994. Factor analysis and related techniques. London: SAGE Publications Ltd.

11. Ljubotina, O.D., \& Ljubotina, D. 2007. Attributions of Poverty among Social Work and Non-social Work Students in Croatia. Croat Med Journal.

12. Malaysia Department of Statistic. 2016. Penyiasatan Pendapatan \& Kemudahan Asas dan Perbelanjaan Isi Rumah (HIS/HES) 2016.

13. Morcol, G. 1997. Lay explanations for poverty in Turkey and their determinants. The Journal of Social Psychology, 137(6): 728-738.

14. Murnizam Halik, Mohd Dahlan A. Malek, Ferlis Bahari, Norlizah Matshah \& Webley, P. 2009. Attribution of poverty among Malaysian students in the United Kingdom. Southest Asia Psychology Journal 1: 22-30.

15. Nasser, R. \& Abouchedid, K. 2001. Causal Attribution Of Poverty Among Lebanese University.

16. Students. Current Research In Social Psychology 6 (14).

17. Nasser, R., Singhal, S. \& Abouchedid, K. 2005. Causal Attributions for Poverty among Indian Youth. Current Research In Social Psychology 11 (1).

18. Nishimwe-Niyimbanira, R. 2014. Household Heads Gender Comparison of Perceived Causes of Poverty in a South African Township. Mediterranean Journal of Social Sciences 5 (21): 299 304.

19. Rozmi Ismail. 2011. Psikologi Sosial. Bangi: Penerbit Universiti Kebangsaan Malaysia.
20. Samuel, Y.A. \& Ernest, K. 2012. Attributions for Poverty: A Survey of Student's Perception. International Review of Management and Marketing 2 (2): 83-91.

21. Wilson, W.J. 1987. The truly disadvantaged: the inner city, the underclass and public policy. Chicago IL: University of Chicago Press.

22. Wollie, C.W. 2009. Causal attributions for poverty among youths in Bahir Dar, Amhara Region, Ethiopia. Journal of Social, Evolutionar, and Cultural Psychology 3 (3): 251-272.

23. Zwick, W. R., \& Velicer, W. F. 1982. Factors influencing four rules for determining the number of components to retain. Multivariate Behavioral Research 17 :253-269.

\section{AUTHORS PROFILE}

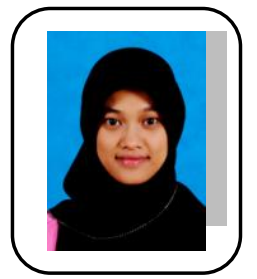

First Author Norizan Hassan is a licensed counselor and a master holder in Psychological Counseling since 2012 from Universiti Kebangsaan Malaysia. She also a former lecturer in a few private collegeas for more than two years. She also had experience for more than two years as Research Assistant. Currently, she looks forward on finishing her study of Doctor of Philosophy in psychology specializing on wellbeing among youth.

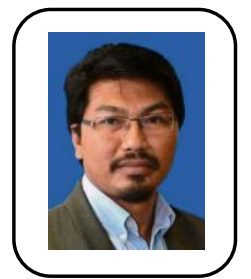

Second Author Prof. Dr. Rozmi Ismail is a Professor and former Head of Psychology Program at Psychology \& Human Well-Being Research Centre), University Kebangsaan Malaysia. He previously served as the Head of Youth Empowerment Program at The Youth Empowerment Center (PERKASA) and President of Malaysia Psychological Association (PSIMA). He graduated with Doctorate of Philosophy in psychology (road safety) and specializes in social psychology and traffic/transport psychology and road safety studies.

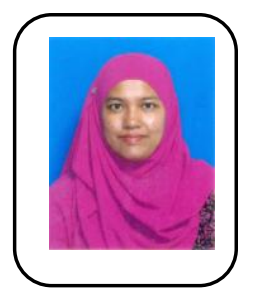

Third Author Dr. Nurul-Azza Abdullah is a lecturer in Psychology and Human Well-Being Research Centre, Universiti Kebangsaan Malaysia. She is a charted psychologist with British Psychology Society and has served in the corporate environment as organizational psychologist for the pass 11 years before she joined UKM in the recent 2 years. She obtained Doctor of Philosophy in social sciences (psychology) with specialisation in industrial/ organizational psychology. 